\title{
CORPO: OBJETO OU SUJEITO?
}

\section{MARCÍLIO DE SOUZA VIEIRA}

Pós-doutor em Artes pela UNESP. Doutor em Educação pela UFRN.

Professor do curso de Licenciatura em Dança da UFRN. Membro dos grupos de pesquisa Estesia e Cirandar.

E-mail: marciliov26@hotmail.com

Resenha submetido em Junho/2016 e aceito em Agosto/2016

NÓBREGA, Terezinha Petrucia. Corporeidade e educação física: do corpo-objeto ao corposujeito. 2a ed. Natal: EDUFRN, 2005.

O livro Corporeidade e educação física: do corpo-objeto ao corpo-sujeito, de autoria da professora Dr.a Terezinha Petrucia da Nóbrega, constitui-se em um significativo esforço e contribuição aos estudos relevantes tanto para a Educação Física, quanto para outras áreas do conhecimento, que se interessam pelos estudos do corpo e pela reflexão filosófica. Por essa razão, o referido livro tem sido utilizado em cursos de graduação e pós-graduação de diversas universidades do país.

Apesar da obra em sua primeira edição ter sido publicada em 2000 e sua segunda edição em 2005, o texto escrito pela professora Petrucia da Nóbrega torna-se exemplar para se pensar o corpo a partir dos preceitos filosóficos e para a área da Educação Física. Nessa direção, compreendo-o como uma produção que deve ser visitada por alunos, professores e interessados nos estudos do corpo. Ela é relevante por denotar um corpo que dialoga com as ciências ditas "duras", com a filosofia, com a educação e com a estética quando apresenta o logos estético como experiência de vida. O corpo, como aponta Almeida, no prefácio da 2a edição "[...] como coágulo da história vivida [...] um tecido poroso que faz copular o tempo, matéria e consciência $[. . .]^{\prime \prime}$.

Terezinha Petrucia da Nóbrega é professora do Departamento de Educação Física e do Programa de Pós-Graduação em Educação da UFRN. É formada em Educação Física (1989) e Filosofia (1995) pela Universidade Federal do Rio Grande do Norte, é especialista em Dança-Educação Física (1991) pela UNIFEC/SP, Mestre em Educação (1995) pela UFRN/RN e Doutora (1999) pela Universidade Metodista de Piracicaba. Realizou Estágio PósDoutoral na PUC São Paulo (2009) e na Université Montpellier I e II ((2009-2010) e Estágio de Pesquisa Sênior na École Normale Superiéure de Paris (2014-2015). Orienta trabalhos ligados às questões corporais e à filosofia. Este livro é fruto de seus estudos no Mestrado em Educação, ocasião na qual apresenta o corpo como uma questão filosófica. O livro Corporeidade e educação física: do corpo-objeto ao corpo-sujeito está em sua segunda edição, publicado pela editora da Universidade Federal do Rio Grande do Norte (EDUFRN), apresentando temas centrais tais como corpo, Filosofia, Educação e Educação Física.

A obra está dividida em quatro capítulos, antecedida de uma introdução. Os capítulos se subdividem em tópicos que norteiam a leitura do livro. No Capítulo I, a autora aborda o corpo no pensamento dos filósofos que influenciaram o pensamento ocidental e que veem o Corpo como objeto, a exemplo dos filósofos Platão, Aristóteles e Descartes, e 
outros filósofos como Nietzche e Merleau-Ponty que apresentam uma concepção de corpo como condição existencial, o Corpo como sujeito; no Capítulo II, aborda o corpo-objeto na perspectiva cartesiana; no Capítulo III, a autora direciona seu olhar para o corpo-sujeito, apresentando uma perspectiva de corpo segundo o pensamento do filósofo francês Merleau-Ponty e no Capítulo IV retoma algumas questões dos capítulos anteriores evidenciando algumas (im)possibilidades (im)completas do corpo humano.

A obra trata do corpo objeto instituído desde Platão até o pensamento de Descartes e do corpo sujeito ressignificado no pensamento de Merleau-Ponty. A autora aponta no texto como este é visto, ainda, na Educação Física, e aponta desafios de pensá-lo na Educação, principalmente na Educação Física. As compreensões de corpo instauradas nesse texto refletem a concepção de corpo a partir da área de estudo citada.

"O olhar dos filósofos sobre o corpo" é o título que a autora dá ao primeiro capítulo. Neste, Nóbrega (2005) aponta as diferentes concepções de corpo segundo o olhar dos filósofos e as construções filosóficas sobre aquele.

Aponta o dualismo corpo e mente preconizados pela Ciência e pela Filosofia que priorizavam a razão privilegiando apenas o espírito, o intelecto, a razão, em detrimento do sensível; e aponta ainda, o pensamento de filósofos como Nietzche e Merleau-Ponty que não coadunam com o pensamento cartesiano sobre o corpo, mas o vê sob a ótica de uma perspectiva ontológica e epistemológica em que o corpo não é objeto, mas que pensa o homem em sua totalidade.

Nesse capítulo inicial e emblemático, a autora dialoga com pensadores tais como, Platão, Aristóteles, Santo Agostinho, São Tomás de Aquino e Descartes, retirando deles as ideias centrais de corpo que permearam o pensamento ocidental do corpo objeto predominando o dualismo corpo e mente privilegiado pela razão. Na deriva desse pensamento, encontra-se pensadores como Nietzche e Merleau-Ponty que apresentam uma concepção de corpo diferente da apresentada pelos filósofos dualistas e veem o corpo numa aproximação entre sujeito e objeto, razão e emoção, colocando o sensível em evidência num processo de humanização desse corpo que não é só maquina, mas que é um corpo vivo, um corpo com linguagem, afetos, sexualidade e história. Tais ideias foram fundamentais para se compreender as concepções de corpo na contemporaneidade, principalmente na Educação Física.

Marcada pelo dualismo, a abordagem de corpo no Ocidente vai encontrar no pensamento de Platão que, só ao intelecto é dado conhecer o mundo sensível e o mundo inteligível. Para ele, o mundo inteligível é o mundo das ideias, do conhecimento perfeito e o corpo seria um obstáculo a essa perfeição, à realização do ideal de bem e de verdade (p. 22). Ainda na antiguidade grega, o dualismo se fará presente na obra de Aristóteles, discípulo de Platão, embora para este filósofo, não ocorra a cisão entre o mundo da matéria e o mundo das ideias.

Na Idade Média, Santo Agostinho e São Tomás de Aquino, vão incorporar as ideias de Platão e Aristóteles e o corpo será visto pelos filósofos-teólogos como símbolo do pecado. "Para estes pensadores cristãos, o homem deveria desligar-se de tudo que o prendesse à sua existência terrena, pois só assim poderia realizar a sua verdadeira essência, espiritual e ultraterrena" (p. 26). 
Com a mudança do mundo antigo, em que a filosofia se preocupava com o mundo das essências, para o mundo moderno, preocupado com a busca do conhecimento certo e seguro, as concepções de corpo vão se tornar mais enfáticas no que diz respeito ao dualismo mente e corpo. Descartes será o maior representante dessa orientação filosófica e influenciará o desenvolvimento da ciência e da educação institucionalizada através da fragmentação entre o saber sensível e o saber lógico.

No bojo do pensamento moderno, vamos encontrar filósofos como Nietzche e Merleau-Ponty preocupados com uma perspectiva de corpo diferente das abordagens da Metafísica ocidental e cartesiana. O corpo para Nietzche "[...] faz-se presente em todos os atos humanos, é a vida em sua plenitude, em toda a sua força. Desprezar o corpo é negar a vida e o próprio ser" (p. 29). Consciência e corpo são valorizados por este filósofo. Para Merleau-Ponty, o sujeito se situa no mundo e o conhece a partir de seu corpo. "O corpo não é objeto, nem ideia, é expressão singular da existência do ser humano que se move. O corpo é sexualidade, é linguagem, é movimento, é obra de arte" (p. 30).

Neste primeiro capítulo, questões como o que é corpo? O corpo é a prisão da alma? Como conhecemos, como aprendemos; por meio das ideias ou por meio das experiências? 0 corpo é uma questão filosófica? Tais questionamentos são pertinentes para se pensar o corpo na Educação, especialmente na Educação física.

No capítulo II, intitulado "A perspectiva cartesiana: o corpo-objeto", a autora apresenta-nos quatro ideias centrais que o norteiam, a saber: A metafísica cartesiana, $\mathrm{O}$ corpo-máquina, A moral cartesiana e A racionalização das práticas corporais.

Na Metafísica cartesiana, Nóbrega (2005) aborda a fundação do cogito na máxima cartesiana expressa pelo "penso, logo existo" que se caracterizou pela busca do conhecimento verdadeiro regido pelas leis da natureza. Essa busca será fundamentada na matemática e só é possível mediante o uso dos atos da inteligência configurados na intuição, na dedução e no método.

Para Descartes, a única certeza contida no cogito é a da existência do eu pensante, certeza esta que irá caracterizar as oposições feitas por este filósofo, da substância pensante e da substância corpórea. "A alma, sendo uma substância pensante e inextensa, opõe-se ao corpo, por este pertencer ao universo da extensão. Dessa forma, tem-se duas realidades distintas e opostas, a saber, a realidade psíquica e a realidade física" (p. 37). Dessa forma, o corpo é colocado como algo contingente, que se ocupa da extensão, enquanto à alma compete conhecer a verdade das coisas, através da intuição puramente intelectual.

A cultura renascentista modificou profundamente o pensamento do homem ocidental. Nessa perspectiva, o pensamento cartesiano, além da Metafísica, contém uma teoria médica. O corpo-máquina vai instaurar o dualismo entre corpo versus mente, próprio do Renascimento, cuja ideia de Descartes influenciou a Ciência, a Filosofia e, sobretudo, a Educação Física. É através do pensamento da medicina cartesiana, diferenciada da medicina tradicional, que a concepção de corpo-máquina contida no pensamento cartesiano está expressa na explicação do funcionamento do corpo. O corpo, dessa forma, é explicado como se fosse uma máquina em funcionamento, como um autômato, cujas funções seguem a disposição dos seus órgãos, sem nenhum aspecto ligado à alma. Em Descartes, a alma está ligada ao pensamento e não ao funcionamento do corpo (p. 39) e todos os membros do corpo humano podem funcionar tal qual como o movimento de um relógio, não havendo 
referências à intencionalidade do movimento, que é considerado apenas no seu aspecto mecanicista. Para Descartes, o corpo atua contra a alma, o que na alma é uma paixão é naquele uma ação, pois o corpo não pensa, daí a necessidade de racionalizar as paixões, tema da Moral cartesiana.

Na Moral cartesiana, Descartes vai reconhecer a ligação estreita entre alma e corpo, sendo esta união não apenas uma soma e sim uma mistura total, embora, para este filósofo, a razão predomina sobre o sensível, apesar de reconhecer na ação humana esta união. Descartes avança nessa temática no sentido de compreender o corpo não apenas em detrimento da alma, mas o aspecto dualista do seu pensamento permanece, principalmente em relação ao conhecimento que vai influenciar consubstancialmente as práticas corporais, sobretudo, nas atividades ligadas à Educação Física.

A leitura que se faz dessas práticas corporais, racionaliza o corpo a um objeto que deve ser disciplinado, reduz o homem à objetividade, apagando o subjetivo, sufocado pelo objetivismo da racionalidade técnico-científico. Há nessa racionalização, a construção da Ciência encontrada principalmente no modelo matemático que para Descartes só a "matemática, por sua ordem e medida, poderia garantir um conhecimento seguro, certo e evidente" (p. 43). Dessa forma, o sensível é desprivilegiado na elaboração do conhecimento e a razão fundada em princípios lógico-matemáticos será guiada pela intuição intelectual e pela dedução. "Nessa perspectiva, o corpo é visto como objeto a ser disciplinado, visando ao aprimoramento físico e moral das pessoas, a eficiência e a produtividade da sociedade industrial" (p. 45).

Na Educação Física, o corpo é tão somente restrito aos padrões de controle e de rendimento, fruto da Educação Física militarista, dos métodos ginásticos e do esporte de rendimento. Marginalizada no contexto intelectual é vista como sinônimo de exercitação física, tratada como atividade sem conhecimento próprio a ser transmitido, reduzindo-se a objetividade, a busca de padrões externos, sem nenhuma significação para quem os realiza. De modo geral, a escola e, sobretudo a Educação Física no âmbito escolar "[...] é cartesiana em suas práticas, na fragmentação do conhecimento disciplinar, na estrutura física, onde não há espaços para o corpo, na valorização do racional e na marginalização das disciplinas que tratam do saber sensível" (p. 51).

Nóbrega (2005) diz que a Educação Física deve superar a tradição mecanicista de corpo e resgatar a linguagem do sensível, vivenciando o corpo não como instrumento ou objeto, mas corpo-sujeito, síntese da presença no mundo, "[...] não o corpo racionalizado do pensamento cartesiano, incorporado pela Ciência e pela Educação, mas o corpo sensível, transversalizado pela percepção do movimento" (p. 53).

Esse corpo é possível quando pensamos nele como corpo-sujeito, sem ser reduzido a sua função mecânica, biológica ou fisiológica, mas um corpo reflexivo, como o meio geral de estar no mundo, como lugar de aprendizagem, tema que a autora aborda no Capítulo III intitulado de "A atitude fenomenológica: o corpo-sujeito" e tem como sub-temas considerações sobre a Fenomenologia como uma filosofia da ação, que reflete o corpo a partir do movimento, critica a Ciência e a própria Filosofia por seu reducionismo, principalmente o Positivismo, por achar que o conhecimento não se reduz a uma única variável. Ainda nesta parte, são abordados o corpo e a motricidade em Merleau-Ponty, com quem a autora dialoga por todo o capítulo. 
Enquanto corrente filosófica preocupada com o ser como um todo, a “[...] Fenomenologia atribui um lugar central à facticidade e as experiências vividas na compreensão do mundo e do $\operatorname{ser}^{\prime \prime}$ (p. 56). Diz respeito à ciência dos fenômenos, busca explicar o mundo, compreender seus sentidos e a relação homem-mundo. Essa relação homem-mundo compreende também o corpo que supera a tradição cartesiana do corpomáquina, do corpo-objeto; compreende o corpo como corpo vivo, dotado de intencionalidade, sujeito e objeto do conhecimento, entrelaçando corpo e mente, razão e emoção, do corpo consigo mesmo, (re) descoberto como possibilidade de reflexão.

"Com o meu corpo, atuo no mundo", assim define Merleau-Ponty o humano a partir de sua realidade corporal. "O ser humano define-se como tal pelo seu corpo e não pelo pensamento. [...] O corpo não está no espaço como um objeto. Ele desenha o espaço, garantindo uma conformação original de acordo com a situação" (p. 63). O corpo, dessa forma, é motricidade, tem um sentido de totalidade que se manifesta no movimento, tem uma intenção, possui uma inteligibilidade, ultrapassa o nível biológico, bem como o universo dos símbolos e cria um mundo simbólico de significações. É no corpo que se localizam os poderes perceptivos "[...] é o lugar de aprendizagem, de apropriação do em torno por parte do sujeito. Uma aprendizagem onde o motor e o perceptivo, o corpo e a consciência compõem um único sistema" (p.68).

Caracterizado pela corporeidade e pela motricidade, o corpo expressa-se como unidade do ser humano em sua realidade existencial e paradoxal, assumindo relações com o tempo e o espaço através do movimento que percebe e é percebido pelo mundo atribuindoIhes sentidos e significados nessa relação de aprendizagem e de conhecimento do mundo. Para a Fenomenologia conhecemos pelos sentidos, pelo corpo; é a partir dele que o sujeito se situa no mundo e o conhece, o corpo então é sexualidade, é afetividade, é linguagem.

Para a Fenomenologia, a educação se dá pelos sentidos, o homem não aprende só com a inteligência, mas também com a orientação da existência e educação dos sentidos. Insistindo na condição corporal do sujeito, a concepção fenomenológica aponta uma educação sensível, que resgata o sujeito de sua alienação individual e coletiva, põe o indivíduo em relação com o mundo e com a representação simbólica deste, sendo seu corpo a primeira relação do homem com o mundo.

O Capítulo IV intitulado "O corpo revisitado" abre-se para novas discussões acerca do corpo, retoma algumas questões dos capítulos anteriores e aprofunda a interpretação merleaupontyana que se dá em relação ao corpo. Ressignifica as diferentes práticas corporais, inclusive na Educação Física e faz uma crítica à Ciência que manipula o corpo. Neste capítulo, a autora evidencia uma (im) possibilidade completa do corpo humano.

A autora dialoga com as Ciências Cognitivas, a Neurociência e com a Fenomenologia de Merleau-Ponty, apresenta como temas centrais a carne como condição humana e afirma que a consciência não sobrevoa o corpo. Considera o conhecimento da Metafísica ocidental e o pensamento cartesiano indispensáveis para se compreender o corpo na atualidade, apesar de ainda, na cultura ocidental considerar-se a compreensão de corpo difundida por Descartes, do corpo como instrumento da alma.

Aponta os avanços das compreensões de corpo nas Ciências Cognitivas, principalmente as dos estudos dos biólogos Maturana e Varela, e da Neurociência com os estudos do biólogo François Jacob. Nessa trajetória, o corpo é visto como híbrido, social, 
tecnobiológico, sendo condição e limite da própria história humana. A autora avança nos estudos da corporeidade e da Educação Física quando aponta novas possibilidades de se olhar o corpo além da perspectiva cartesiana, um corpo que é sentido, é linguagem, é estar no mundo percebendo-o e sendo percebido por ele.

Aborda a temática do corpo com propriedade, servindo para os campos de estudo da Educação Física e da Filosofia, redimensionando e ressignificando o pensar corpo na contemporaneidade. $O$ diálogo com os autores enfatiza essa ressignificação mostrando-nos que é pelo corpo em movimento que aprendemos as tarefas mais importantes para o ser humano.

As reflexões abordadas pela autora nos induz a questionamentos tais como: Como o pensamento se relaciona com o corpo? O que é a mente, o pensamento? Ele está localizado em alguma parte do corpo? Qual a compreensão de corpo que temos? Como ocorre a aprendizagem no corpo? O que fazer agora que o corpo existe? O corpo é uma questão filosófica? Fiquemos como aponta a autora com o exercício da dúvida. "Exercício este que possibilitou a invenção da Filosofia e que pode assegurar ao corpo uma certa medida de segredo e de intimidade e à Educação Física a possibilidade de reinventar a sua própria história no domínio do gesto, da cultura de movimento e da educação do corpo" (p.104).

\section{REFERÊNCIA}

NÓBREGA, Terezinha Petrucia. Corporeidade e educação física: do corpo-objeto ao corposujeito. 2 ${ }^{a}$ ed. Natal: EDUFRN, 2005. 